\title{
Rheological behavior of PMN gels for solid freeform fabrication
}

\author{
Aylin Şakar-Deliormanlı ${ }^{\mathrm{a}, *}$, Erdal Çelik ${ }^{\mathrm{b}}$, Mehmet Polat $^{\mathrm{a}}$ \\ a Izmir Institute of Technology, Chemical Engineering Department, Urla, Izmir, Turkey \\ ${ }^{\mathrm{b}}$ Dokuz Eylul University, Metallurgy and Materials Engineering Department, Izmir, Turkey
}

\section{A R T I C L E I N F O}

Article history:

Received 5 December 2007

Received in revised form 31 March 2008

Accepted 8 April 2008

Available online 22 April 2008

\section{Keywords:}

Lead magnesium niobate

Suspensions

Colloidal gels

Shaping

\begin{abstract}
A B S T R A C T
Lead magnesium niobate (PMN) is a relaxor ferroelectric material and have widespread applications in the manufacture of multilayer electronic devices such as ceramic capacitors, actuators and transducers. The dielectric constant of this electrostrictive material is much higher than the well known ferroelectric barium titanate. However, aqueous processing of PMN is not investigated yet especially for the novel wet shaping fabrication. In this study, concentrated aqueous colloidal PMN gels have been designed to use in the robocasting process. Concentrated PMN suspensions were stabilized by polyacrylic acid and then gelation induced by changing the $\mathrm{pH}$ or ionic strength of the suspension or by addition of a cationic polyelectrolyte to the system. Through this procedure it was essential to understand the solid-liquid transition under shear to explore the feasibility of forming without excessive use of polymers. Therefore, rheological response of the samples having a gel network was investigated. Results showed that gelation induced by cationic polyethylene imine or by multivalent salts were successful methods in preparation of PMN gels. However, gelation induced by changing the $\mathrm{pH}$ of the suspension was challenging due to ion dissolution from PMN surface.
\end{abstract}

(c) 2008 Elsevier B.V. All rights reserved.

\section{Introduction}

The manufacturing of three-dimensional micro-periodic structures from polymeric or colloidal materials is important for several technologies. These structures may find applications in tissue engineering [1-3], microfluidic networks, actuators, sensors, and other electronic ceramic devices [4-9]. Some of these applications require use of functional materials such as ferroelectric ceramics.

Lead magnesium niobate (PMN) is a relaxor ferroelectric material and especially used in the manufacturing of electrostrictive actuators and transducers [10-12]. Electrostrictive actuator is a category of smart material transducers. In actuators it is desirable to enhance the displacement while maintaining the load bearing capability. This can be achieved by manipulating the geometry of simple shape actuators into more complex geometries $[13,14]$. Direct write technologies are able to produce 2D or $3 \mathrm{D}$ periodic structures to use in these application areas [15-21].

Robocasting is an extrusion-based, direct write technique. It is a solid free form fabrication method that utilizes colloidal systems of low organic content [21-23]. Previously, Lewis and co-workers conducted intensive research on the robocasting of alumina [24],

\footnotetext{
* Corresponding author. Tel.: +90 232 7506697; fax: +90 2327506645 .

E-mail address: aylindeliormanli@iyte.edu.tr (A. Şakar-Deliormanlı).
}

barium titanate [25] and lead zirconate titanate [26-28] powders and produced different geometries to be used in different applications [21].

In robocasting, the processing steps include formulation of the colloidal ink, the printing, and finishing operations. In the first step preparation of uniform, highly concentrated and low viscosity slurry is crucial. High solids loading is necessary because it increases the green body density, and also minimizes drying shrinkage. This is followed by a fluid-to-gel transition which is necessary for the printing operation. In order to maintain structural integrity robocasting relies on the rheology of the deposited paste $[6,8,9]$. The important rheological parameters for the printing ink include the apparent viscosity, yield stress under shear and compression, and viscoelastic properties [4,23]. Furthermore, colloidal inks developed for the robotic deposition must able to flow through the nozzle and then set immediately to keep the shape retention. In other words, the particle network must be able to resist stresses arising from capillary tension $[6,21,22]$. Therefore, preparation of colloidal inks that are capable of flowing through the nozzles of varying size and then setting immediately to facilitate shape retention of the deposited features is crucial in direct writing techniques $[4,23]$.

The aim of this study is to prepare and characterize the rheological behavior of PMN gels to use in solid freeform fabrication. Following the design of high quality inks with desired rheological properties three-dimensional structures were produced by robotic deposition. 

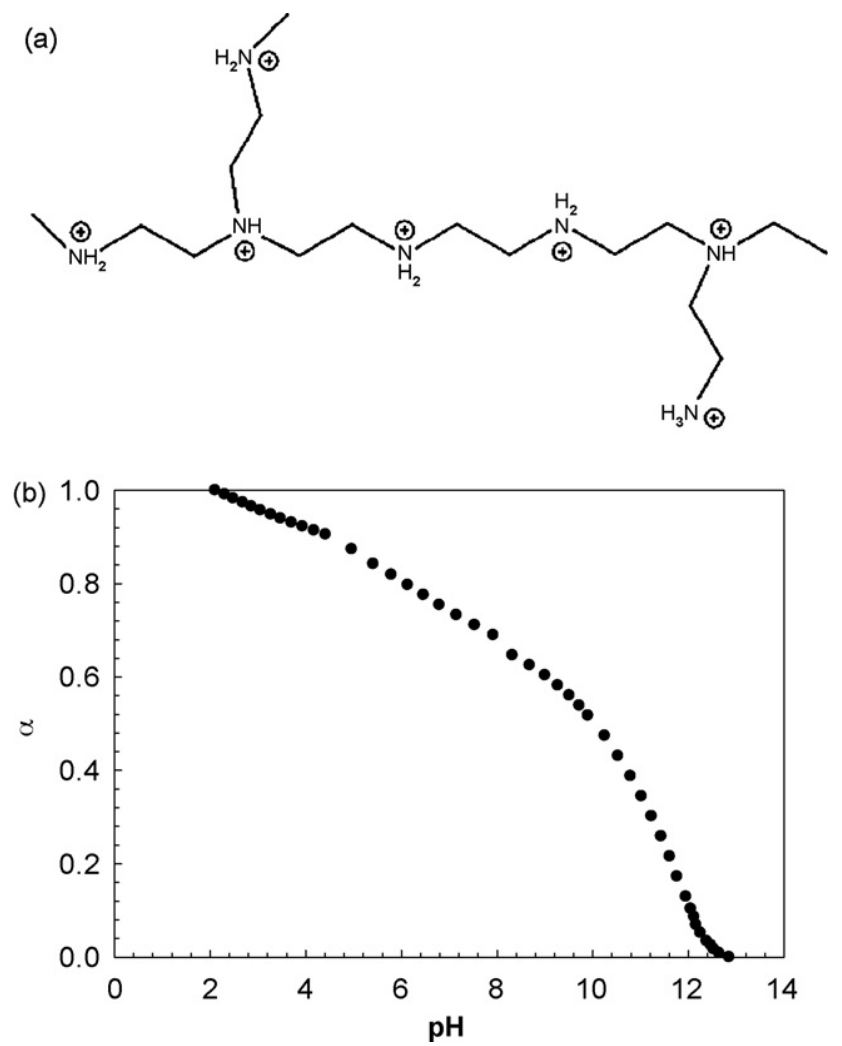

Fig. 1. (a) Chemical structure of a PEI molecule [43]. (b) The ionization degree of PEI solution as a function of $\mathrm{pH}$.

\section{Experimental}

\subsection{Materials}

Lead magnesium niobate, $\mathrm{Pb}\left(\mathrm{Mg}_{1 / 3} \mathrm{Nb}_{2 / 3}\right) \mathrm{O}_{3}$ powder produced by combustion spray pyrolysis method was provided by Praxair Specialty Ceramics, WA, USA. Powder purity is $99.9 \%$ as reported by the manufacturer. Bulk density (Helium pycnometer Micromeritics 1330), and the BET surface area (Micromeritics ASAP 2400) of the powder are measured to be $7.967 \mathrm{~g} / \mathrm{cm}^{3}$ and $1.168 \mathrm{~m}^{2} / \mathrm{g}$, respectively. Particle size distribution of the powder was measured using a particle size analyzer (Horiba CAPA-700) and the $\mathrm{d}_{50}$ of the powder was around $2.0 \mu \mathrm{m}$. Polyacrylic acid (Polyscience Inc., USA) supplied as a $40 \mathrm{wt} \%$ aqueous solution served as the dispersant for the PMN particulate suspensions. Hydroxypropyl methylcellulose, HPMC (Methocel F4M, Dow Chemical Co., Midland, MI) was used as a viscosifier and binder. Cationic polyelectrolyte poly(ethylene imine) PEI $\left(M_{\mathrm{W}} \sim 600 \mathrm{~g} / \mathrm{mol}\right)$ was supplied (Polysciences, Inc., USA) as a concentrated liquid (99\%). Figs. 1(a) and 2 show the chemical structure of poly (ethylene imine) and polyacrylic acid used in the study. Potentiometric titrations were performed in order to investigate the fraction of ionized sites in PEI as a function of $\mathrm{pH}$. During the experiments all $\mathrm{pH}$ adjustments were made using certified $1.0 \mathrm{M}$ solutions of $\mathrm{KOH}$ and $\mathrm{HNO}_{3}$ (Fisher Scientific). Stock solutions of $1.0 \mathrm{M}$ magnesium chlo-

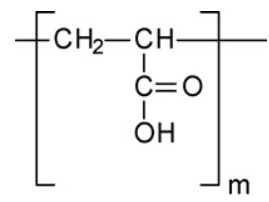

Fig. 2. Chemical structure of PAA [30]. ride (Fisher Scientific, USA), 1.0 M zinc acetate (Fisher Scientific, USA) and 3.0 M potassium chloride (Fisher Scientific, USA) were prepared with deionized water and these solutions were utilized through the experiments. Nanopure water having conductivity of $16.4(\Omega \mathrm{cm})^{-1}$ obtained from Millipore, Direct $Q$ was used for all experiments.

\subsection{PMN gel preparation}

Stable colloidal suspensions ( $55 \mathrm{vol} . \%$ ) were prepared by adding $0.25 \mathrm{wt} \%\left(1.1 \mathrm{mg} / \mathrm{m}^{2}\right)$ PAA in terms of the dry weight basis of the PMN powder. Suspensions were ultrasonicated for 1.30 min with on-off intervals (550 Sonic Dismembrator, Fisher Scientific, Pardubice, Czech Republic). Then suspensions were stirred for $24 \mathrm{~h}$ to ensure the complete adsorption of PAA onto powder surface. An aliquot of HPMC stock solution was added to yield a final cellulose concentration of $5 \mathrm{mg} / \mathrm{ml}$. Suspensions were homogenized using planetary centrifugal mixer (Thinky ARE-250, Japan) for $3 \mathrm{~min}$.

Gelation induced using three different methods developed by Lewis and co-workers. These methods were utilized previously for the controlled gelation of alumina, barium titanate, and lead zirconate titanate suspensions [6,24-28,34]. In the first method, inks were prepared by adding poly(ethylene imine) (PEI) to the system. Poly(ethylene imine) is a highly branched polyamine that contains primary, secondary, and tertiary amine groups in a $\sim 1: 2: 1$ ratio. Over the $\mathrm{pH}$ range of interest, $\mathrm{PEI}$ is positively charged with approximately $50 \%$ of these groups protonated at $\mathrm{pH} \sim 6$ [4]. In the second approach, the $\mathrm{pH}$ of the system was reduced below $\mathrm{pH} 9$ to obtain a strong gel network. Since the ionization of PAA molecules is very sensitive to the variations in the suspension $\mathrm{pH}$ and the hydrodynamic radius of PAA decreases as the $\mathrm{pH}$ decreases [29,30]. In the last method, monovalent and divalent salts were introduced to the system and their ability to construct a gel network was evaluated. The method is based on the principle that hydrodynamic radius of PAA decreases as the ionic strength of the solution increases [30]. Prior the direct writing process PMN gels were homogenized again using planetary centrifugal mixer for $3 \mathrm{~min}$.

\subsection{Rheological measurements}

Rheological measurements were performed using a stress controlled rheometer (Bohlin CS-50, Sweden) with C14 geometry (cup inner diameter: $16 \mathrm{~mm}$ and bob outer diameter: $14 \mathrm{~mm}$ ). To prevent wall slip the geometry having the serrated walls was used during the measurements. Additionally, to reduce sample evaporation a custom-made solvent trap was utilized. Each measurement required a sample size of $3.0 \mathrm{ml}$, which was loaded into the cell using an automatic pipette. Slurry temperature was kept constant at $25^{\circ} \mathrm{C}$ during the measurements using a temperature bath.

For the dynamic (oscillation) measurements, a pre-shear of $10 \mathrm{~s}^{-1}$ was applied for a period of $60 \mathrm{~s}$ to induce the same shear history for all samples. Then the samples were left undisturbed for $5 \mathrm{~min}$ to reach the equilibrium. Oscillatory measurements were performed in order to understand the strength and yield information of the gels. Amplitude sweep measurements were conducted between 0.1 and $100 \mathrm{~Pa}$. Fifty measuring points were selected for each measurement.

The ink rheology was investigated as a function of $\mathrm{pH}, \mathrm{PEI}$ and salt concentration and correlated to the electrostatic interactions of the PAA-coated particles. By adjusting the $\mathrm{pH}$ of the PMN/water system or by adding PEI or increasing the ionic strength, a fluid-to-gel transition was induced that resulted in a concentrated viscoelastic gel. 

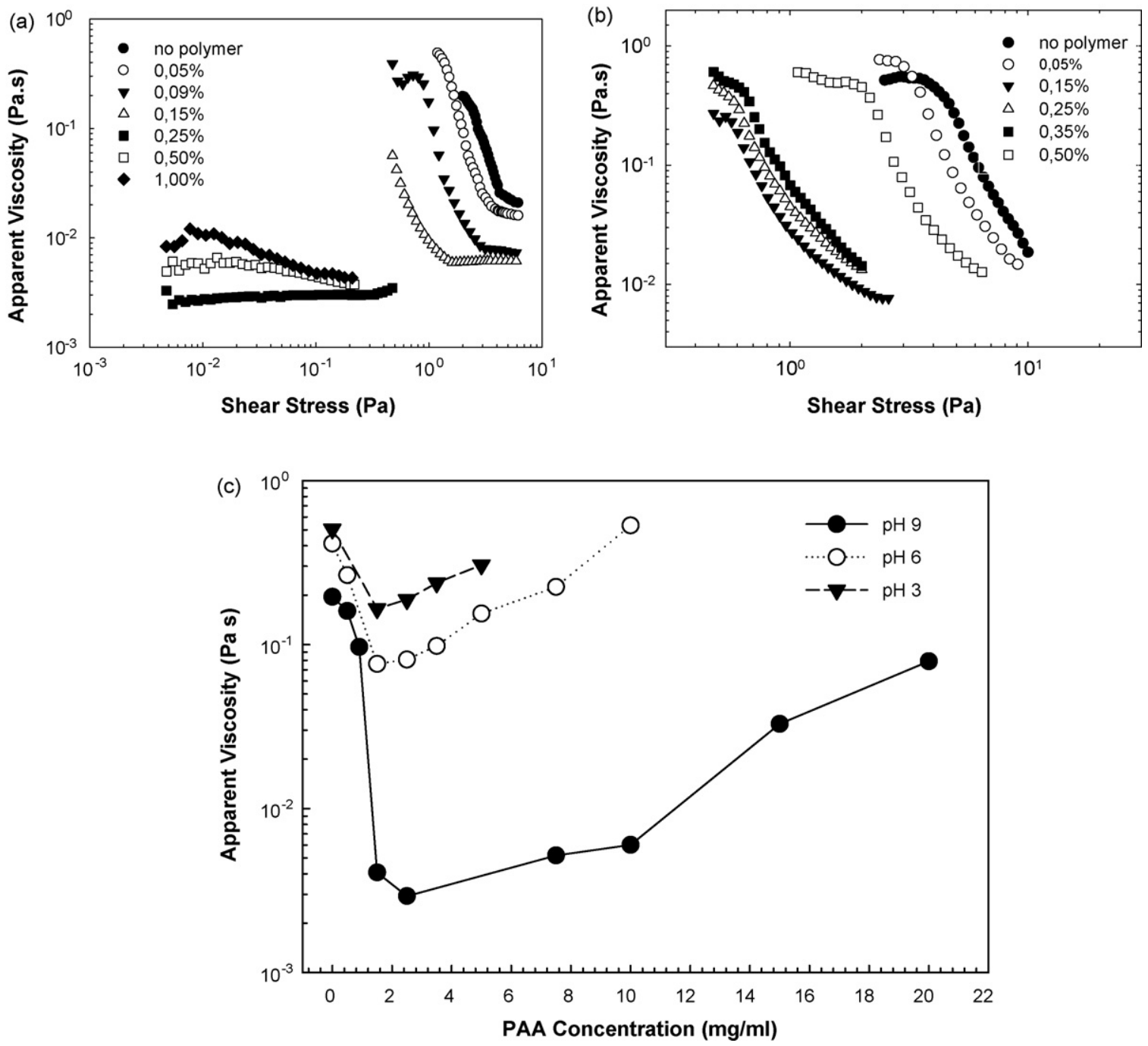

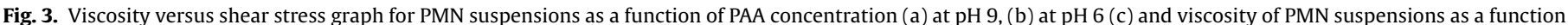
of polyelectrolyte concentration and $\mathrm{pH}$.

\subsection{Direct writing}

Periodic lattices were produced using a robotic deposition apparatus (JL2000, Robocasting Enterprises, Inc., Albuquerque, NM). The 3 -axis motion of the $x-y$ and $z$-stages was independently controlled by a custom-designed, computer-aided program (RoboCAD 2.0) that allowed for the construction of complex, 3D structures. For the deposition the ink was housed in a syringe and deposited through a stainless steel nozzle $(D=100,200$ and $500 \mu \mathrm{m})$ at a volumetric flow rate of $7.5 \mathrm{~mm} / \mathrm{s}$. A constant pressure was applied to induce the ink flow through the nozzle. The deposition process was carried out under a non-wetting oil to prevent drying during assembly. All test structures were allowed to rest undisturbed in this bath for $30 \mathrm{~min}$ after deposition was completed, and then they were dried at room temperature for $24 \mathrm{~h}$ followed by a drying at $80^{\circ} \mathrm{C}$ for overnight.

\section{Results and discussion}

\subsection{Effect of PAA on the dispersion behavior of PMN suspensions}

Fig. 3a shows the effect of PAA on the flow behavior of PMN suspensions (20vol.\%) at $\mathrm{pH} 9$. For the system a critical concentration $\left(c^{*}\right)$ of polyelectrolyte was identified corresponded to the amount required to promote a transition from strongly shear thinning behavior to nearly Newtonian behavior. According to Fig. 3a, PMN suspensions show a shear thinning behavior at low polymer concentrations however, starting from a certain concentration a transition to Newtonian behavior was observed. The $c^{*}$ value corresponding to the lowest suspension viscosity was obtained at $0.25 \mathrm{wt} \%$ polymer concentration ( $1.1 \mathrm{mg} \mathrm{PAA} / \mathrm{m}^{2}$ of PMN). The flow curve of the PMN suspensions in the presence of PAA at $\mathrm{pH} 6$ showed shear thinning behavior and fits to Carreau model (See Fig. 3b). It is an alternative to well known Cross model. The model equation is given below [32]:

$\eta=\eta_{\infty}+\frac{\left(\eta_{0}-\eta_{\infty}\right)}{\left(1+(k \dot{\gamma})^{2}\right) n}$

where $\eta_{0}$ and $\eta_{\infty}$ are the viscosity at low and high shear rates, $k$ is a time constant and $n$ is a behavior index. Model parameters as a function of PAA concentration is tabulated in Table 1.

Similarly, Fig. $3 \mathrm{c}$ demonstrates the effect of $\mathrm{pH}$ on the stability of PMN suspensions in the presence of PAA. Accordingly, a gradual rise was observed in apparent viscosity as the $\mathrm{pH}$ of the suspensions decreased. Especially at $\mathrm{pH} 3 \mathrm{PAA}$ was not capable to disperse PMN suspensions in contrast it caused a strong agglomeration in the system. It is well known that the carboxylic acid groups on PAA 
Table 1

Carreau model parameters for PMN suspensions in the presence of PAA at $\mathrm{pH} 6$

\begin{tabular}{lllll}
\hline PAA (\%) & $\eta_{0}$ & $\eta_{\infty}$ & $k$ & $n$ \\
\hline 0 & 0.6240 & 0.01931 & 0.101 & 0.5693 \\
0.05 & 0.6426 & 0.008955 & 0.2519 & 0.4948 \\
0.15 & 0.4018 & 0.005622 & 0.6554 & 0.4619 \\
0.25 & 0.6968 & 0.008678 & 1.185 & 0.4543 \\
0.35 & 0.8089 & 0.008836 & 1.256 & 0.4504 \\
\hline
\end{tabular}

dissociate to produce negative charge. For each carboxylic group of PAA degree of dissociation increases with increasing $\mathrm{pH}$ and complete ionization occurs at $\mathrm{pH} 9$. On the other hand, at $\mathrm{pH} 3$ the PAA molecule has no charge $[29,30]$.

The increase in PMN suspension viscosity at low pH values is mainly because of the surface charge of PMN, ionization degree of PAA and complex formation between the PAA and dissolved divalent cations from PMN surface. Ion bridging interactions may cause rapid aggregation of PAA molecules and PAA stabilized particles [30]. Detailed discussion on the effect of dissolved cations on the stability of PMN particles can be found elsewhere [31,39].

\subsection{Gelation with cationic polyelectrolyte}

A cationic polyelectrolyte, polyethylene imine was used to create gelation in PAA-coated PMN suspensions. For a successful ink design, PEI concentration should be below the concentration needed to form monolayer coverage around the PMN particle. Because only at a critical concentration PEI acts as a bridging flocculant otherwise in the case of full surface coverage it may serve as a dispersant.

Experiments were performed at $\mathrm{pH} 9$ since at this $\mathrm{pH}$ surface charge of the PMN particles are positive $\left(\mathrm{pH}_{\text {IEP }} 9.8\right.$ at 20 vol.\%) [31] and anionic polyelectrolyte PAA is fully [29] and PEI is partially ionized. Titration experiments showed that PEI is fully charged at about $\mathrm{pH} 2$ (Fig. 1b) and at $\mathrm{pH} 6$ it is positively charged with approximately $50 \%$ of the amine groups are protonated. However, rheological measurements indicate that at $\mathrm{pH} 6 \mathrm{PMN}$ suspensions were over gelled which is not suitable to use in direct writing process. Therefore, printing inks were prepared at $\mathrm{pH} 9$ to reduce the yield strength of the gel network having appropriate flow properties for deposition.

Effect of PEI concentration on the viscosity of concentrated PMN suspensions in the presence of HPMC is shown in Fig. 4a. As it is clearly indicated in the figure, gelation starts at a PEI concentration of $0.04 \mathrm{mg} / \mathrm{m}^{2}$ ( $5 \mu \mathrm{l}$ PEI $40 \mathrm{wt} \%$ for $20 \mathrm{ml}$ of PAA-coated PMN suspension). As the PEI concentration increases to $0.06 \mathrm{mg} / \mathrm{m}^{2}$ viscosity of the gel network also increases. Suspensions showed a typical shear thinning behavior above the yield stress and the curves best fit with the Hershel-Bulkley model. When stressed beyond its yield point $\left(\tau_{\mathrm{y}}\right)$, a colloidal gel exhibits shear thinning flow behavior due to the attrition of particle-particle bonds within the gel, as described by the Hershel-Bulkley model [32]:

$\tau=\tau_{\mathrm{y}}+K \dot{\gamma}^{n}$

where $\tau$ is the shear stress, $n$ is the shear thinning exponent $(<1), K$ is the viscosity parameter, and $\dot{\gamma}$ is the shear rate. Although it is not demonstrated in Fig. 4a at very high PEI concentration a decrease in viscosity was observed.

Possible flocculation mechanism induced by the PEI addition can be explained as follows: PEI molecule approaches the negatively charged polyacrylic acid on the surface of the PMN particles. Complexation reactions allowed for PEI adsorption can be as a second layer on the top of the PAA layer or by incorporation into the PAA layer. But even if incorporated into the PAA layer PEI may protrude
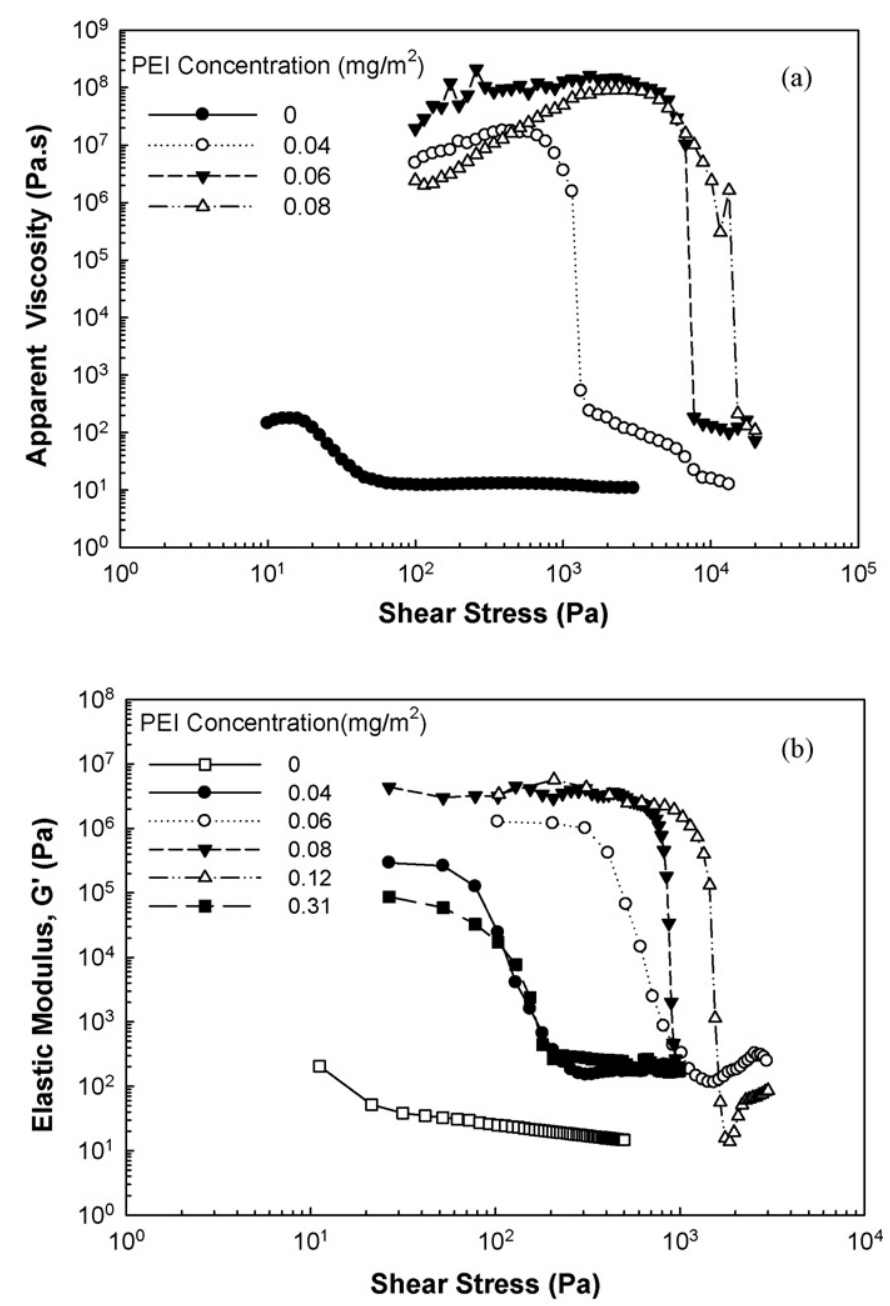

Fig. 4. (a) Viscosity and (b) elastic modulus versus shear stress graph of PMN slurries as a function of PEI concentration, 55 vol.\% PMN, pH 9 , in the presence of $3 \mathrm{mg} / \mathrm{ml}$ HPMC.

sufficiently from the particle surface to enable bridging between the neighboring particles [33-35].

According to Sato and Ruch flocculation by bridging mechanism may occur in different ways. One of these mechanisms is due to the low surface coverage by polymer adsorption. By this way there are more chances for adsorption of polymer extending from one particle to another particle. This bridging flocculation occurs only at low polymer concentrations where the surfaces of the particles have less than half of their saturation value of the adsorbed flocculant [36].

Fig. 4b shows the effect of PEI concentration on the elastic modulus of the concentrated PMN gels (55 vol.\%). Again the high elastic modulus value at a PEI concentration of $0.04 \mathrm{mg} / \mathrm{m}^{2}$ indicates the gel like behavior. On the other hand, at a PEI concentration of $0.31 \mathrm{mg} / \mathrm{m}^{2}$ a dramatic decrease was observed in viscoelastic properties. It was hypothesized that at this concentration PEI concentration exceeds the critical concentration and electrostatic stabilization starts since all particles covered by PEI molecules.

\subsection{Gelation with $\mathrm{pH}$ modification}

Fig. 5a and $\mathrm{b}$ show the effect of $\mathrm{pH}$ modification on the apparent viscosity and elastic modulus of the PAA-coated PMN suspensions. At $\mathrm{pH}$ values higher than the IEP of PMN, suspensions exhibited nearly Newtonian behavior. Starting from the $\mathrm{pH} \sim 8.7$ a dramatic 

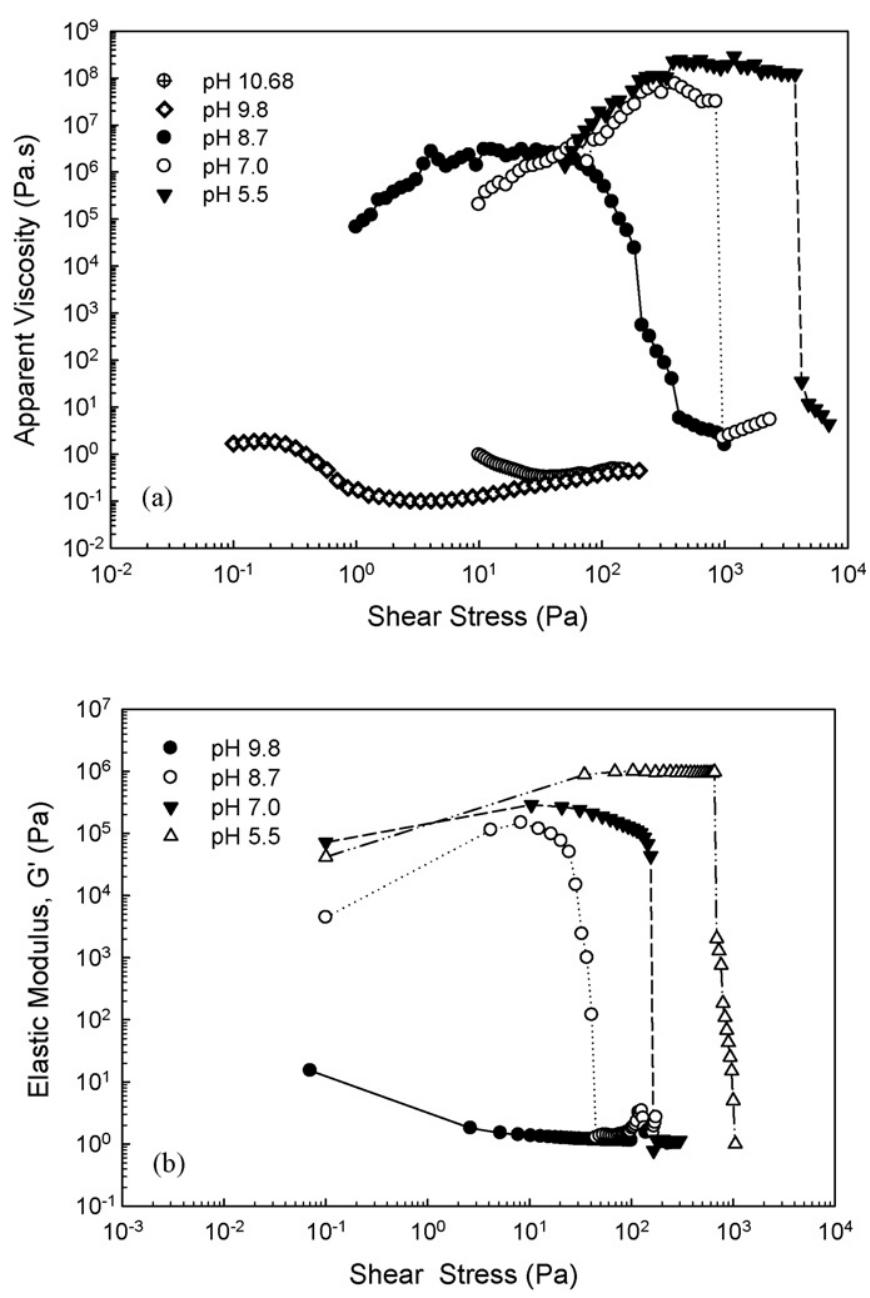

Fig. 5. Effect of pH modification on the (a) viscosity and (b) elastic modulus of PMN suspensions ( $55 \mathrm{vol} . \%$ ) in the presence of PAA.

increase in apparent viscosity was observed. As the $\mathrm{pH}$ decreased to 5.5 , viscosity reached to $10^{8} \mathrm{~Pa}$ s. Elastic modulus of the gels at this $\mathrm{pH}$ was also very high. However, the gels prepared under these conditions were not suitable to use in direct writing process because of the poor flow properties. The reason of the strong coagulation observed at low pH values in PAA-coated PMN suspensions was attributed to decrease in ionizable groups in PAA molecules. As it was discussed previously, PAA molecule consists ionizable carboxylic acid groups and it is fully negatively charged at pH 9 [37-38]. Therefore, as the pH decreases below 9, PAA caused a strong destabilization in concentrated PMN suspensions due to decrease in ionization.

Results of the current study also showed that gelation of PMN suspensions using $\mathrm{pH}$ modification method may be challenging due to leaching of lead and magnesium ions from the particle surface especially at acidic $\mathrm{pH}$ values. Previous study of Deliormanli et al. showed that $\mathrm{Pb}^{2+}$ and $\mathrm{Mg}^{2+}$ ions are partially dissolve from PMN surface as a function of $\mathrm{pH}$ and solids concentration. The solubility of these cations from the surface reaches maximum especially at $\mathrm{pH}<3$. On the other hand, $\mathrm{Nb}^{5+}$ have a rather low dissolution under the same conditions [39]. Furthermore, during acid titration the reactivity of PMN particles may lead to a time dependent $\mathrm{pH}$ rise and this cause partial restabilization of the PMN suspensions. The reason of the $\mathrm{pH}$ rise may be due to capture of the $\mathrm{Pb}^{2+}$ ions by the carboxylic acid groups on the adsorbed PAA which drive equilibrium towards the alkaline region. Similarly, PMN suspensions
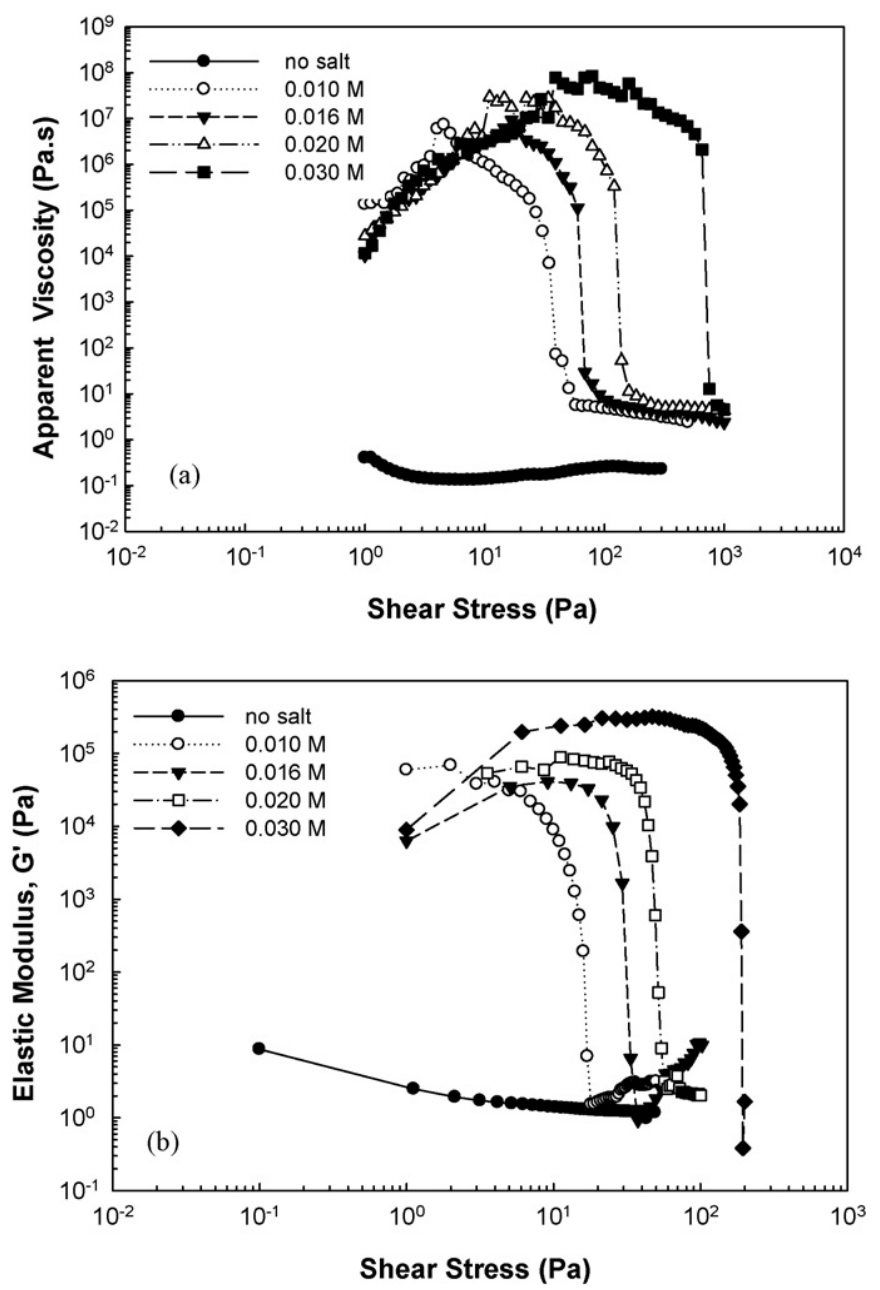

Fig. 6. Effect of $\mathrm{MgCl}_{2}$ on the (a) viscosity and (b) elastic modulus of the PMN suspensions (55 vol.\%) in the presence of PAA, $\mathrm{pH} 9$.

most probably consume the protons from solution. This may be attributed to the adsorption of protons from solution onto the PMN surface which should yield a positive surface charge at these low $\mathrm{pH}$ values. Such increase in the $\mathrm{pH}$ due to consumption of protons must be associated by the cation dissolution from the PMN surface at the acidic $\mathrm{pH}$ range. Such effect would be more pronounced with increasing solids content [40].

\subsection{Gelation with ionic strength modification}

In the study, magnesium chloride and zinc acetate were tested to investigate the effect of divalent salt additions on the gelation behavior of PAA-coated PMN suspensions. Fig. 6a and b shows the effect of $\mathrm{Mg}^{2+}$ ion concentrations on the viscosity and elastic modulus of the colloidal PMN inks. The PAA-coated PMN suspensions exhibited a strong rise in both their low shear apparent viscosity and degree of shear thinning flow behavior with increasing $\mathrm{Mg}^{2+}$ ion concentration. Although the rise in viscosity may be attributed to the complex formation between the divalent ions and the PAA there is also a possibility for a complex formation between $\mathrm{MgCl}_{2}$ and PMN particle surface. According to the previous study of Deliormanli et al. electrophoretic mobility measurements of the PMN suspensions showed that in the presence of $\mathrm{MgCl}_{2}$, as a background electrolyte, isoelectric point of PMN was depended on the salt concentration which means that there is $\mathrm{Mg}^{2+}$ adsorption onto the surface [39]. 

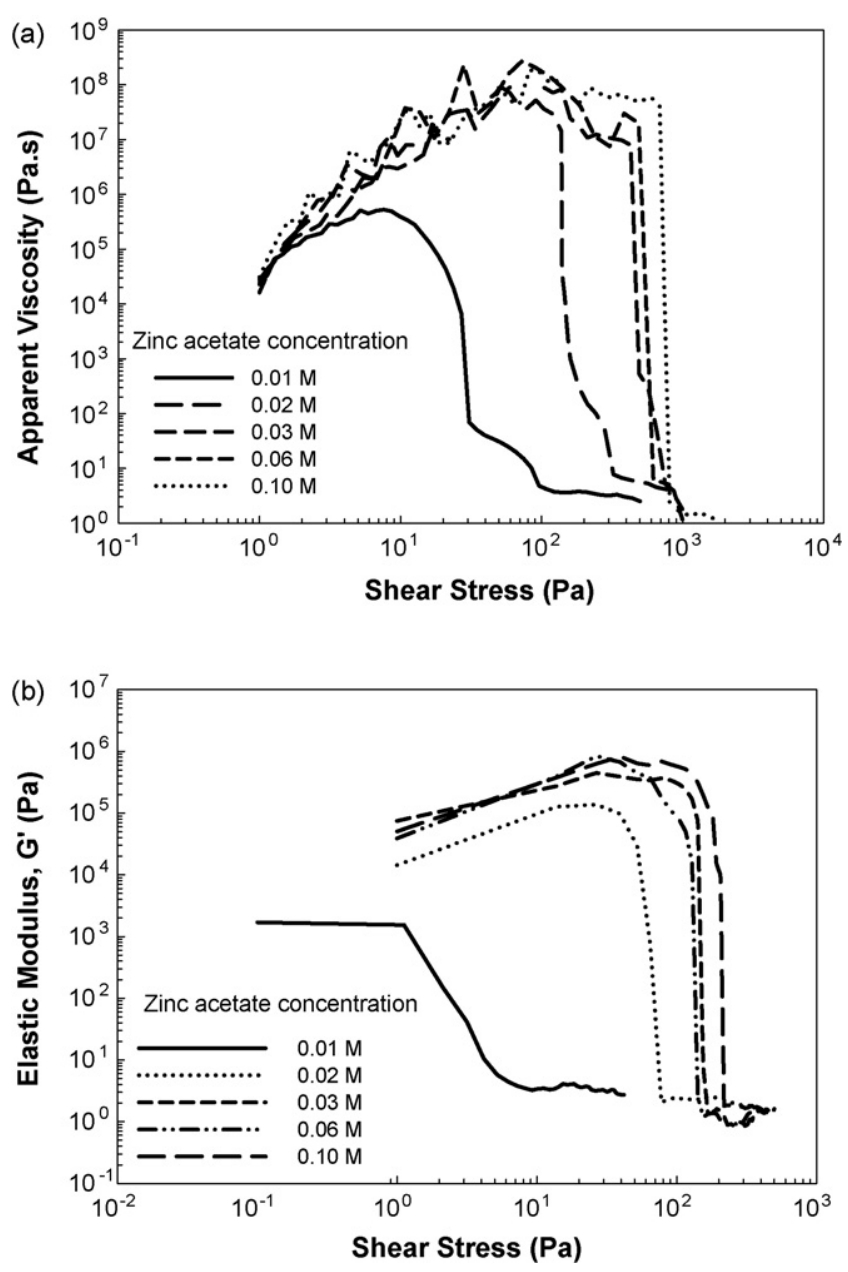

Fig. 7. Effect of zinc acetate concentration on the (a) viscosity and (b) elastic modulus of the PAA-coated suspensions (55 vol.\%), pH 9.

Similar results were obtained for PAA-coated PMN suspensions containing zinc acetate. As it is shown in Fig. 7a and b there is a dramatic rise in apparent viscosity and elastic modulus of the PMN suspensions as the zinc acetate concentration increase. On the other hand, as the applied shear stress was increased a linear viscoelastic region (low shear stress, $G_{\text {eq }}^{\prime}$ plateau) preceded a decrease in $G^{\prime}$ at the shear yield stress, $\tau_{\mathrm{y}}$. For $\tau>\tau_{\mathrm{y}}$ the particle network was ruptured and the suspension became fluid. The reason for the steep rise in viscosity and the elastic moduli was attributed to the decrease in PAA adlayer thickness with increasing ionic strength. The negatively charged PAA-coated particles are stable under low ionic strength but rapidly aggregate at high ionic strength conditions. This behavior is also closely related with the valence of the ions introduced to the system $[37,41]$.

In this study to compare the effects of monovalent and divalent salt species on the gelation behavior of PMN suspensions, the viscosity and elastic modulus was examined as a function of ionic strength in the presence of $\mathrm{KCl}$ and divalent salts. The ionic strength was calculated according to following equation [42]:

$[I]=\frac{1}{2} \sum_{i} n_{i} z_{i}^{2}$

where $n_{i}$ is the molar concentration of ionic species and $z_{i}$ the valency of the ion. Results showed that the addition of divalent salt species led to the destabilization of the PAA-coated PMN suspensions. According to the Manning counterion condensation theory,

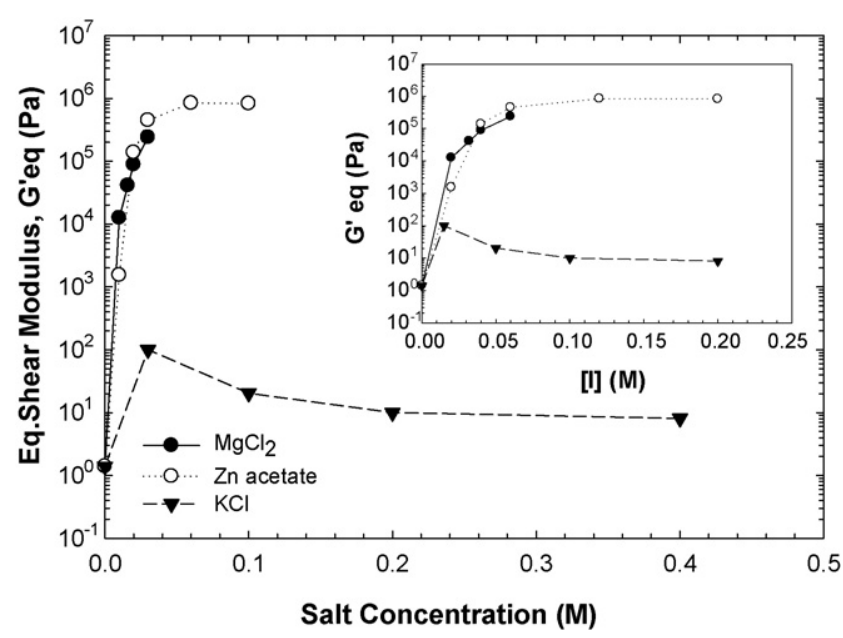

Fig. 8. Effect of monovalent and divalent salts on the viscoelastic response of PAAcoated PMN suspensions as function of salt concentration and ionic strength.

a fraction of the charged groups along the polyelectrolyte backbone of PAA will be neutralized when counterions are present in solution. Counterion condensation occurs due to electrostatic interactions between oppositely charged side groups and counterion species, which inhibit counterion diffusion away from the polyelectrolyte chains. Condensed counterions screen the negative charges associated with the carboxylic acid groups therefore decrease the repulsive electrostatic interactions between like-charged, adsorbed PAA-based dispersants on different particles. Polyelectrolye species can undergo additional attractive interactions by sharing counterions. This is commonly referred to as ion bridging [33,35]. Because both screening efficiency and bridging interactions intensify with increasing counterion valency, divalent counterions are more effective at promoting attractions between polyelectrolyte species than monovalent ones.

Fig. 8 demonstrates the effect of monovalent salt $(\mathrm{KCl})$ on the gelation behavior of concentrated PMN suspensions. Even at very high salt concentrations such as $0.2 \mathrm{M} \mathrm{KCl}$ any flocculation was not observed in the system. Experiments were also performed at lower salt concentrations such as $0.03 \mathrm{M} \mathrm{KCl}$. Although it is not demonstrated in the same figure, at low salt concentrations again $\mathrm{KCl}$ did not cause destabilization. For monovalent salt additions such as $\mathrm{KCl}$ the only available mechanism for reducing the electrosteric stabilization between the PMN particles is screening the charge between the particles and the adsorbed PAA layer. This screening causes a reduction in the repulsive electrostatic interactions between the particles and possibly a small contraction of the adsorbed PAA layer because of the conformational changes [37].

Therefore, it is possible to conclude that monovalent counterions such as $\mathrm{K}^{+}$only screens the negatively charged $\mathrm{COO}^{-}$groups, on the other hand divalent counterions such as $\mathrm{Zn}^{2+}$ and $\mathrm{Mg}^{2+}$ can promote the aggregation through the ion bridging effects between PAA adsorbed on the particle surface [25,34]. Results of this study showed an increase in the low shear apparent viscosity of the PAAstabilized suspensions containing $\mathrm{Mg}^{2+}$ or $\mathrm{Zn}^{2+}$ ions compared to those with $\mathrm{K}^{+}$ions at the same ionic strength. This observation indicates that increased ionic strength is not solely responsible for destabilizing the PAA-coated PMN suspensions but the valence of the ions has also important effects on the observed gelation $[25,34]$.

\subsection{Preparation the $3 D$ shapes by direct writing}

In the study depositions down to $100 \mu \mathrm{m}$ were successfully performed. The ink flowed through the nozzle at a volumetric flow rate 


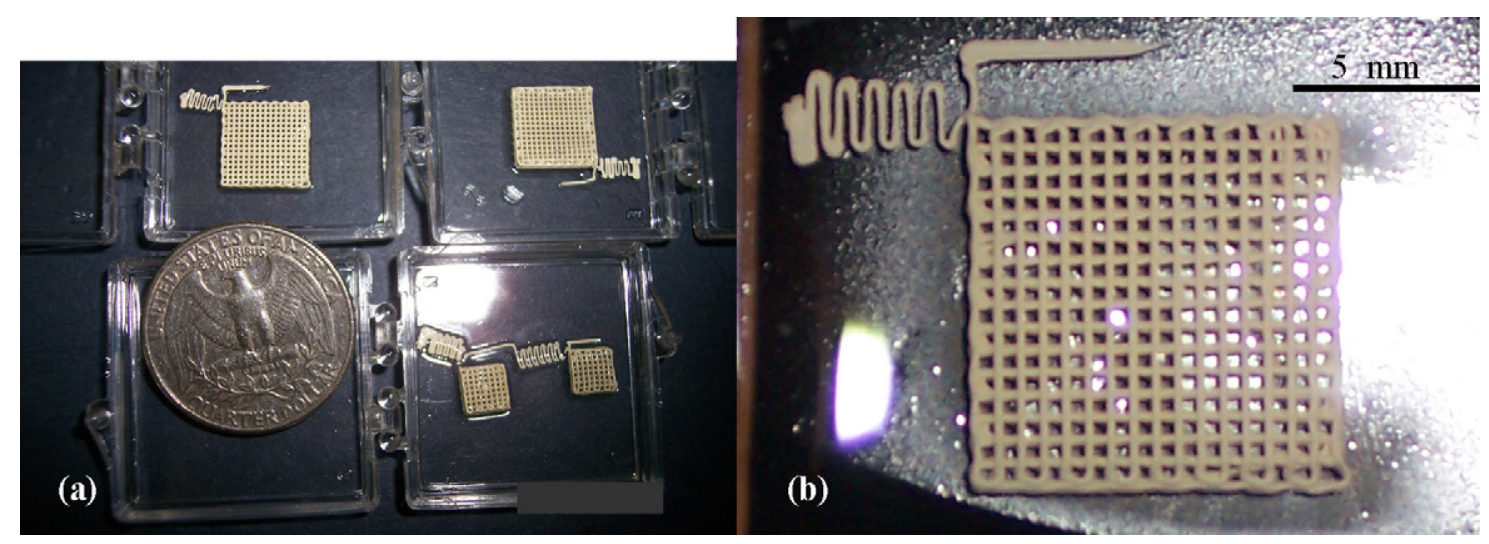

Fig. 9. Three-dimensional PMN lattices produced by robotic deposition technique (a) in oil reservoir and (b) after drying.

required to maintain a constant deposition speed of $7.5 \mathrm{~mm} / \mathrm{s}$. As the ink exits the nozzle, it formed a rod-like filament with a rigid core-fluid shell architecture that helps shape retention. To prevent changes in PMN gel rheology due to water evaporation the deposition process was carried out in an oil reservoir. Fig. 9 shows the 3D lattices produced by robocasting method. The pictures were taken just after deposition step therefore the structures are still in oil reservoir. Results showed that it was possible to create well shaped, uniform lattices having rod sizes in the range of $100-500 \mu \mathrm{m}$ using PMN ink in the presence of 0.04 or $0.06 \mathrm{mg} / \mathrm{m}^{2}$ PEI. At a PEI concentration of $0.08 \mathrm{mg} / \mathrm{m}^{2}$ the yield stress of the PMN ink was too high therefore, at this concentration the flow properties of the ink was poor. Above this value some difficulties were observed in shape retention due to decrease in destabilization of PMN inks.

\section{Conclusions}

Concentrated aqueous colloidal PMN gels were produced to use in the robocasting process. For this purpose PMN suspensions were stabilized by polyacrylic acid and then gelation induced by changing the $\mathrm{pH}$ or ionic strength of the suspension or by addition of a cationic polyelectrolyte to the system. Results showed that gelation induced by cationic polyethylene imine or by multivalent salts were successful in preparation of PMN gels. However, gelation induced by the $\mathrm{pH}$ modification method was challenging due to ion dissolution from PMN surface. Results showed that complex PMN shapes having rod size down to $100 \mu \mathrm{m}$ can be successfully produced by robocasting process to be used in microelectronic applications.

\section{Acknowledgements}

Authors would like to thank Prof. Dr. Jennifer A. Lewis for use of the robotic deposition device and laboratory facilities in Materials Science and Engineering Department at University of Illinois at Urbana Champaign, USA. Contributions of Dr. John Bukowski are gratefully acknowledged. The project is supported by the State Planning Organization of Turkey (DPT) and The Scientific and Technological Research Council of Turkey (TUBITAK, NATO-A2).

\section{References}

[1] D.L. Cohen, E. Malone, H. Lipson, L. Bonassar, 3D direct printing of heterogeneous tissue implants, Tissue Eng. 12 (2006) 1325-1335.

[2] S. Das, S. Hollister, in: K.H.J. Buschow, R.W. Cahn, M.C. Flemings, B. Ilschner, E.J. Kramer, S. Mahajan (Eds.), Tissue Engineering Scaffolds, Encyclopedia of Materials-Science and Technology, Elsevier, 2002.

[3] T.-M.G. Chu, J.W. Halloran, S.J. Hollister, S.E. Feinberg, Hydroxyapatite implants with designed internal architecture, J. Mater. Sci.: Mater. Med. 12 (2001) 471-478.
[4] G.M. Gratson, Colloidal and polyelectrolyte inks for direct-write assembly of 3D periodic structures, PhD Thesis, 2005.

[5] G.M. Gratson, J.A. Lewis, Polyelectrolyte inks for direct-write assembly of 3D microperiodic scaffolds, Langmuir 21 (2005) 457-464.

[6] J.A. Lewis, Direct ink writing of 3D functional materials, Adv. Funct. Mater. 16 (2006) 2193-2204.

[7] M. Geissler, Y. Xia, Patterning: principles and some new developments, Adv. Mater. 16 (2004) 1249-1269.

[8] A.Safari, M. Allahverdi, E.K. Akdogan, Solid freeform fabrication of piezoelectric sensors and actuators, J. Mater. Sci. 41 (2006) 177-198.

[9] A. Safari, J. Cesarano, P.G. Clem, B. Bender, Fabrication of advanced functional electroceramics components by layered manufacturing (LM) methods, in: Proceedings of the 13th IEEE International Symposium on Applications of Ferroelectrics, Japan, 2002, pp. 1-6.

[10] S. Gentil, D. Damjanoviç, N. Setter, $\mathrm{Pb}\left(\mathrm{Mg}_{1 / 3} \mathrm{Nb}_{2 / 3}\right) \mathrm{O}_{3}$ and $(1-x) \mathrm{Pb}$ $\left(\mathrm{Mg}_{1 / 3} \mathrm{Nb}_{2 / 3}\right) \mathrm{O}_{3}-x \mathrm{PbTiO}_{3}$ relaxor ferroelectric thick films: processing and electrical characterization, J. Electroceram. 12 (2004) 151-161.

[11] H.S. Tzou, H.J. Lee, S.M. Arnold, Smart materials, precision sensors/actuators, smart structures, and structronic systems, Mech. Adv. Mater. Struct. 11 (2004) 367-393.

[12] J.A. Moulson, J.M. Herbert, Electroceramics Materials Properties and Applications, Chapman \& Hall, 1990.

[13] S.E. Prasad, A. Ahmed, T.A. Wheat, The role of smart materials and structure in robotics, Smart Mater. Struct. (1998) 133-147.

[14] G.H. Blackwood, M.A. Ealey, Electrostrictive behavior in lead magnesium niobate (PMN) actuators part I: materials perspective, Smart Mater. Struct. 2 (1993) 124-133.

[15] P. Calvert, Ink jet printing for materials and devices, Chem. Mater. 13 (2001) 3299-3305.

[16] P. Calvert, R. Crockett, Chemical solid freeform fabrication: making shapes without molds, Chem. Mater. 9 (1997) 650-663.

[17] L. Xiaogang, F. Lei, H. Seunghun, V.P. Dravid, C.A. Mirkin, Arrays of magnetic nanoparticles patterned via dip pen nanolithography, Adv. Mater. 14 (2002) 231-234.

[18] J. Yoo, M. Cima, E. Scahs, S. Suresh, Fabrication and microstructural control of advanced ceramic components by three dimensional printing, Ceram. Eng. Sci. Proc. 16 (1995) 755-762.

[19] R.E. Brennan, S. Turcu, A. Hall, N.M. Hagh, A. Safari, Fabrication of electroceramic components by layered manufacturing, Ferroelectrics 293 (2003) 3-17.

[20] K.F. Teng, M.A. Azadpour, H.Y. Yang, Rapid prototyping of multichip packages using computer controlled ink-jet direct write, in: IEEE Proceedings of the 38th Electronics Components Conference, 1988, pp. 326-329.

[21] J.A. Lewis, J.E. Smay, J. Stuecker, J. Cesarano III, Direct ink writing of three dimensional ceramic structures, J. Am. Ceram. Soc. 89 (2006) 35993609.

[22] J.A. Lewis, Direct-write assembly of ceramics from colloidal inks, Curr. Opin. Solid State Mater. Sci. 6 (2002) 245-250.

[23] J. Cesarano III, R. Segalman, P. Calvert, Robocasting provides moldless fabrication from slurry deposition, Ceram. Ind. 148 (1998) 4.

[24] S.L. Morissette, J. Cesarano III, J.A. Lewis, D.B. Dimos, Solid freeform fabrication using chemically Suspensions, US Patent No.: 6,454,972 (2002).

[25] Q. Li, J.A. Lewis, Nanoparticle inks for directed assembly of three dimensional periodic structures, Adv. Mater. 15 (2003) 1639-1643.

[26] J.E. Smay, G.M. Gratson, R.F. Shepherd, J. Cesarano III, J.A. Lewis, Directed colloidal assembly of 3D periodic structures, Adv. Mater. 14 (2002) 1279-1283.

[27] J.E. Smay, J. Cesarano III, J.A. Lewis, Colloidal inks for directed assembly of 3-D periodic structures, Langmuir 18 (2002) 5429-5437.

[28] S.L. Morissette, J.A. Lewis, Direct write fabrication of $\mathrm{Pb}(\mathrm{Nb}, \mathrm{Zr}, \mathrm{Ti}) \mathrm{O}_{3}$ devices: influence of paste rheology on print morphology and component properties, J. Am. Ceram. Soc. 84 (2001) 2462-2468. 
[29] V.A. Hackley, Colloidal processing of silicon nitride with poly(acrylic acid): adsorption and electrostatic interactions, J. Am. Ceram. Soc. 80 (1997) 2315-2325.

[30] G.H. Kirby, PAA/PEO comb polymer effects on the rheological property evolution in concentrated cement suspensions, PhD Thesis, 2003.

[31] A.M. Deliormanlı, E. Çelik, M. Polat, The isoelectric point of lead magnesium niobate, J. Am. Ceram. Soc. 90 (2007) 3314-3317.

[32] G.R. Larson, The Structure and Rheology of Complex Fluids, Oxford University Press, 1999.

[33] R.R. Netz, D. Andelman, Neutral and charged polymers at interfaces, Phys. Rep. 380 (2003) 1-95

[34] S.S. Nadkarni, J.E. Smay, Concentrated barium titanate colloidal gels prepared by bridging flocculation for use in solid freeform fabrication, J. Am. Ceram. Soc. 89 (2006) 96-103.

[35] D.H. Napper, Steric stabilization, J. Colloid Interface Sci. 58 (1977) 390-407.

[36] T. Sato, R. Ruch, Stabilization of Colloidal Dispersions by Polymer Adsorption, Surfactant Science Series, 9, Marcel Dekker, USA, 1980.
[37] H.G. Kirby, D. Harris, Q. Li, J.A. Lewis, Polyacrylic acid-polyethylene oxide comb polymer effects on $\mathrm{BaTiO}_{3}$ nanoparticle suspension stability, J. Am. Ceram. Soc 87 (2004) 181-186.

[38] J. Cesarano III, I.A. Aksay, Processing of highly concentrated aqueous $\alpha$-alumina suspensions stabilized with polyelectrolytes, J. Am. Ceram. Soc. 71 (1988) 1062-1067.

[39] A.M. Şakar-Deliormanlı, E. Çelik, M. Polat, Solubility and aging of lead magnesium niobate in water, Ceram. Int., in press.

[40] U. Paik, A.V. Hackley, Influence of solids concentration on the isoelectric point of aqueous barium titanate, J. Am. Ceram. Soc. 83 (2000) 2381-2384.

[41] A. Sakar-Deliormanlı, E. Celik, M. Polat, Adsorption of anionic polyelectrolyte and comb polymers onto lead magnesium niobate, Colloids Surf. A: Physicochem. Eng. Asp. 316 (2008) 202-209.

[42] R.J. Hunter, Foundations of Colloid Science, Oxford, UK, 1995.

[43] K. Andersson, L. Bergstrom, Effect of the cobalt ion and polyethyleneimine adsorption on the surface forces between tungsten oxide and cobalt oxide in aqueous media, J. Am. Ceram. Soc. 85 (2000) 2404-2408. 